\title{
Multiobjective optimization in ERP system design
}

\author{
Alexander Feofanov ${ }^{1}$, and Nikolay Baranov ${ }^{2, *}$ \\ ${ }^{1}$ Moscow State University of Technology "STANKIN", 127055 Moscow, Russia \\ ${ }^{2}$ Saint-Petersburg State University of Civil Aviation, 196210 Saint-Petersburg, Russia
}

\begin{abstract}
Practically in any real situation, there are several goals that can contradict each other. So many tasks solved by ERP system have more than one criterion. And also, it is very important to use multiobjective optimization methods, which allow for information about the decision maker's preferences.
\end{abstract}

In today's world one of enterprise's success requirements is ERP system use.

The ERP system provides effective management of technological processes, functioning governing authorities functioning and production resources distribution of both an individual enterprise and a distributed technological system [1].

Enterprise activity and planning estimation is based on more than a dozen criteria: the production plan implementation in terms of products range, in terms of volume, labor productivity, implementation plan, profitability, etc. [2, 3].

The continuous complication of industrial relations, the adoption to new technologies significantly complicate the creation of modern complex control systems for industrial enterprises, characterized by large dimensions, multiobjectivelity, hierarchical structure, the presence of subsystems of various nature, which makes it relevant to study ways to solve multiobjective problems arising in the synthesis of multi-level control systems of an industrial enterprise [4].

Following the works [4-6], we will consider the main points of multiobjective optimization in ERP system design

Industrial enterprise management processes research brings about the concept of a complex management system with a given hierarchical structure.

Currently, the most common is a hierarchical structure with two levels of management. A feature of this structure is the combination of centralized system management with local management of individual objects. Management functions are divided between the central authority, which implements the algorithm for global management of the system, and local authorities, each of which solves the problems of managing a certain subset of objects in accordance with the control actions of the central authority.

The main outline for the formation of the hierarchy of management tasks is as follows: the solution of the upper-level task determines the goals for the lower-level tasks and leads to the implementation of information operations, including financial ones. Control

\footnotetext{
${ }^{*}$ Corresponding author: baranov@post.com
} 
decisions directly related to changes in the course of production, that is, setting the sequence of operations and their intensity, refer to the lowest level.

Solving the problem of each level requires obtaining new information about the state of the system by the time the corresponding solution begins to be developed. The hierarchy of the system of control tasks to a certain extent determines the hierarchical structure of the information and control system. Solving problems of a higher level, as a rule, refers to the functions of higher levels in the organizational structure.

Hierarchical control systems can differ from each other by a combination of connections between subsystems and the composition of subsystems, depending on their behavior. The functioning of the system is considered in relation to the purpose of the upper level subsystem. The functioning of the subsystems of each level is structured in such a way as to satisfy the goals of the subsystems of the upper level in relation to them. Each of the subsystems, when solving problems of self-government, determines its capabilities for the planned period using more reliable information. Taking these capabilities into account, the task of coordinating lower-level subsystems is solved in order to fulfill the task of the upper-level subsystem. If the solution to such a problem is impossible, then a conflict situation arises between two adjacent levels, which leads to the solution of the rescheduling problem in the upper level subsystem, that is, to the redistribution of resources or a change in the values of control actions. If this problem is solvable, then a control action is issued on the subsystems of the lower level, which solve their problems, etc.

The found control actions in each of the subsystems make it possible to solve the problem of the upper-level subsystem. Thus, the reference values of the output variables of each of the subsystems will be determined, relative to which the problem of operational control should be solved under the action of external disturbances on the subsystems of the lower levels. In this case, it is necessary to consider the problems of the accuracy of the functioning of the investigated hierarchical system.

To effectively solve the multiobjective optimization problems, it is first of all necessary to build a multiobjective mathematical model, which then needs to be optimized, having previously selected the most suitable method for this.

In the general case, multiobjective problems do not have an unambiguous general solution. Therefore, many ways are proposed to give a multiobjective problem a particular form that allows a single general solution. Naturally, these solutions are generally different for different methods. Therefore, it is extremely important in solving a multiobjective problem to substantiate this type of its statement.

Various options are used to simplify the multiobjective problem. There are some of them:

- Conditional maximization (not the global extremum of the integral criterion is found, but the local extremum of the main criterion).

- Search for an alternative with given properties.

- Finding the Pareto set.

- Reduction of a multi-criteria problem to a single-criteria problem by introducing an integral criterion.

Obviously, the optimal solution can only belong to the area of compromises, since in the area of agreement the solution can and should be improved according to the corresponding criteria.

Highlighting the area of compromise narrows the area of possible solutions, but in order to select one single solution option, the meaning of the optimization operator should be disclosed or a compromise scheme should be chosen. If we assume that all local criteria are normalized, then the main compromise schemes are the principle of uniformity, the principle of fair assignment, the principle of highlighting one criterion to be optimized, and the principle of successive assignment. 
Region of compromise is a subset of the admissible set of solutions in which all solutions belonging to it cannot be improved simultaneously by all local criteria. The optimal solution, chosen on the basis of a multiobjective approach, regardless of the chosen principle of optimality, should always belong to the region of compromise. Otherwise, it can be improved and is therefore not optimal

It follows from this that the region of compromise is the region of potentially optimal compromises. Thus, when choosing a solution based on a vector efficiency criterion, it is possible to restrict the search for an optimal solution to the region of compromises, which, most often, is much narrower than the entire area of possible solutions.

It should be noted that in all the problems of choice and decision-making methods considered above, the problem was to find the best ones in the initial set under the given conditions, i.e. optimal in a sense, alternatives.

The idea of optimality is central and has become a part of the practice of designing and operating technical systems. At the same time, this idea requires a careful attitude towards ourselves when we try to transfer it to the area of complex, large and weakly deterministic systems control, such as, for example, socio-economic systems.

One should take into account the strong simplification of these models, which in the case of complex systems can no longer be neglected, as well as the fact that the degree of adequacy of these models in the case of complex systems is actually unknown. Therefore, it is not known what purely practical significance this optimization has. The high practicality of optimization in technical systems should not give rise to the illusion that it will be just as effective when optimizing complex systems. Substantial mathematical modeling of complex systems is very difficult, approximate and imprecise.

The methods for the multiobjective optimization problem (MOO-problem) solving are very diverse. There are several ways to classify these methods. Consider a classification based on the content and form of using additional information about the preferences of the decision-maker, according to which the following classes of methods are distinguished:

- Methods without taking into consideration the preferences of the decisionmaker.

- A posteriori methods.

- A priori methods.

- Interactive methods.

The methods of each of these classes have their own advantages and disadvantages. Methods can belong to different classes, and various combinations of these methods are also possible.

A posteriori methods involve the introduction of information about their preferences by the decision maker into the MOO-system after a certain set of effective solutions has been obtained.

The main disadvantage of posterior methods is that they are computationally expensive.

In addition, with an increase in the number of effective solutions, the problem of choosing a single solution from the presented set becomes more laborious for the decisionmaker.

In fact, a priori methods in their "pure" form are often used, since it is often very difficult for decision makers to formulate their preferences before starting to solve the problem.

Interactive methods consist of a set of iterations, each of which includes an analysis stage performed by a decision-maker and a calculation stage performed by the MOOsystem. By the nature of the information received by the MOO-system from the decisionmaker at the analysis stage, classes of interactive methods can be distinguished, in which the decision-maker:

- Directly assigns the weights of particular optimality criteria.

- Limits the values of particular optimality criteria. 
- Performs an assessment of the alternatives proposed by the MOO-system.

Among the interactive methods for solving the MOO-problem, the most promising are methods based on solution estimates. Based on the form in which the decision-maker evaluates decisions.

This class of methods includes:

- Methods in which the decision-maker evaluates decisions in terms of "excellent", "very good", "good", etc., or methods based on assessments of the preference function;

- Methods in which the decision-maker evaluates decisions in terms of "better", "worse", "the same", or methods based on pairwise comparison of decisions [9].

For the decision-maker, these forms of setting preferences are the most simple and convenient. In recent years, there have been trends in the development of this particular class of methods, which is due to the need for active participation of decision-makers in solving complex modern engineering problems.

\section{References}

1. E.B. Frolov, A.N. Feofanov, Vestnik Mashinostroeniya, v. 5, pp. $84-86$ (2017). (in Russian).

2. I.Yu. Yunin, A.N. Feofanov, A.V. Kapitanov, V.G. Mitrofanov, Svarochnoe Proizvodstvo, v. 8, pp. 49-51 (2011). (in Russian).

3. N.E. Baranov, A.N. Feofanov, Tekhnologiya Mashinostroeniya, v. 2 (200), pp. 65-71. (2019). (in Russian).

4. E.A.Hadzaragova, Metodi issledovaniya $i$ proektirovaniya system upravleniya promishlennimi predpriyatiymi (Terek, Vladikavkaz, 2001). (in Russian).

5. D.T. Shvarc, Nauka i Obrazovanie, v. 04, pp. 245-264 (2013). (in Russian).

6. V.V. Belyakov, M.E.Bushueva, V.I.Sagunov, Mnogokriterialnaya optimizatsiya $v$ zadachah otsenki podvizhnosti, konkurentosposobnosti avtotraktornoy tehniki $i$ diagnostiki slozhnih tehnicheskih sistem (NGTU, N.Novgorod, 2001). (in Russian). 